\title{
DOSSIER
}

\section{OTRAS DELINCUENCIAS EN AMÉRICA \\ LATINA, 1880-1920}

\section{PRESENTACIÓN}

Cosi tutte le forme d'illecito, da quelle più sornione a quelle più feroci si saldavano in un sistema che aveva una sua stabilità e compattezza e coerenza e nel quale moltissime persone potevano trovare il loro vantaggio pratico senza perdere il vantaggio morale di sentirsi con la coscienza a posto [...].

cosi la controsocietà degli onestiforse sarebbe riuscita a persistere ancora per secoli, in margine al costume corrente, senza altra pretesa che di vivere la propria diversità.

(Italo Calvino, “Apologo sull'onestà nel paese dei corrotti”).

$\mathrm{F}^{1}$ presente dossier lleva por título "Otras delincuencias en América Latina” porque estudia algunos fenómenos delictivos desatendidos por la investigación histórica sobre esta región. Entre las expresiones de esa delincuencia figuraron la falsificación, la estafa y el fraude. Sin tratarse necesariamente de trasgresiones inéditas, dicha tríada de delitos económicos se transformó, de forma notoria, durante las últimas décadas del siglo xix y las primeras del xx. Tal vez porque se trató de manifestaciones de una criminalidad que evolucionó de la mano del capitalismo financiero, con la consabida ampliación y diversificación de documentos de cambio, pero que también se vio 
potenciada por la aceleración de los traslados de personas tanto de rutas marítimas como terrestres. ${ }^{1}$

En las cada vez más densas concentraciones urbanas, también se aceleró el tiempo y se incrementó el volumen de información por medio de tecnologías de comunicación como el cablegrama submarino, el telegrama y, en forma incipiente, el teléfono. Finalmente, falsificar fue un negocio que encontró oportunidades en el perfeccionamiento de numerosas técnicas de reproducción e impresión, como el grabado, la litografía, el fotograbado y la fototipia. Muchas de las técnicas mencionadas tan sólo mejoraron en eficiencia, calidad y escala. Todo ello repercutió en expresiones delincuenciales cuyos límites, según expresiones de una prensa crecientemente sensacionalista, fueron la imaginación de los propios transgresores, quienes encontraron un nicho de oportunidades en falsificar, defraudar y estafar, un repertorio de ilegalidades propiciado por cierta porosidad en la administración de justicia. Se trató en buena medida de delitos con alta impunidad, baja penalidad y, en no pocas ocasiones, los presuntos responsables fueron favorecidos por medio de sobornos, complicidades y otros fenómenos de corrupción.

Tal como si se tratase de empresas, los protagonistas de estas delincuencias calcularon costos, riesgos y beneficios. Bien pudiera considerárseles como manifestaciones tempranas del delito organizado o simplemente como negocios delictivos cuyos integrantes ejecutaron sus labores como profesionales. En su artículo, Diego Galeano reconstruye la trayectoria de una familia de inmigrantes italianos dedicada a fabricar y circular

\footnotetext{
1 Sólo para ofrecer un panorama general, las primeras líneas férreas comenzaron a construirse en la década de 1840, pero especialmente después de 1870 despuntaría el desarrollo del ferrocarril. A comienzos de esa década las vías férreas en América de Sur se extendían por poco más de 1000 kilómetros, mientras que para 1900 sumaban más de 16000 . Argentina, México y Chile fueron los países que finalizaron el periodo con la red ferroviaria más amplia de América Latina.
} 
billetes falsos, esto es, un grupo de personas que desempeñó una actividad sobremanera rentable y, desde luego, tan ilegal como necesaria cada vez que escaseaba circulante para solventar intercambios comerciales en el espacio atlántico sudamericano. De esa manera, el clan Chiarini se presenta como una empresa dedicada a falsificar papel moneda y que explotó redes de parentesco además de operar con la confianza y el silencio de los compradores.

A esas redes trasnacionales de delincuentes correspondía también una serie de intercambios que resultaron de la cooperación policial internacional, cuyo rastro ha quedado en archivos, revistas y otras publicaciones que posibilitaron un flujo de información cada vez más dinámico en -y entre- América del Sur y Europa, particularmente Francia. De estos temas se ocupa el artículo de Marília Rodrigues de Oliveira, quien por un lado muestra el creciente interés de las policías por investigar el fraude y la falsificación mientras que, por el otro, analiza el intercambio de saberes entre policías en ambos lados del Atlántico con base en la figura de Elysio de Carvalho. Detalla, entonces, cómo emergió y circuló toda una taxonomía para renombrar y producir conocimiento criminológico sustentado en los gabinetes de identificación.

El científico no sería el único lenguaje alterado por los delitos económicos, sino que también los imaginarios populares y la prensa moderna exhibieron hondas preocupaciones por las estafas, latrocinios y contubernios dentro de una variedad de negocios considerados ilícitos. Eso sugiere el trabajo de Daniel Palma, que a partir de numerosos casos muestra las prácticas de latrocinio asociadas al mundo de las élites económicas y burguesías chilenas. Desplegadas tanto en la región nortina en pleno apogeo salitrero, como en despojos de tierras en territorio mapuche, dichas prácticas fueron asimiladas al mundo de la injusticia y explotación en la lira popular, expresión que por medio de una gramática refería, en términos propios, la delincuencia de cuello blanco. 
Así, varios consideraron todavía más graves los delitos contra la propiedad cometidos por clases medias y altas ya que, en comparación con aquellos realizados por los sectores pobres, eran realmente pocas las ocasiones en que se procedía judicialmente en su contra. Ésa fue una de las consideraciones ventiladas en procesos judiciales contra una serie de estafas a las compañías de seguros de vida en México, en las que también fue preponderante la organización del delito, las redes de parentesco y el capitalismo financiero.

Si bien desarrollan ejes y discusiones particulares que les son propios, los artículos abonan a un campo especializado en el delito, las policías, la justicia y el castigo en América Latina. Desde el último tercio del siglo xx, la investigación histórica sobre estos temas ha conformado un campo sumamente dinámico y ha desarrollado, cuando menos, cuatro ejes que ostentan enfoques y agendas de investigación propios. Sin desplazar necesariamente viejos problemas, el interés sobre estos temas ha incorporado tanto el bandidaje rural como la criminalidad urbana e instituciones de control que, por si fuera poco, han producido información sobre sí mismas y sobre la sociedad: tribunales y juzgados, comisarías de policía y cárceles, por denominar genéricamente instituciones de segregación y encierro sumamente diversas.

A dichas posibilidades se han sumado propuestas para debatir e historiar la criminalidad y la transgresión social que, en ocasiones, la sobreespecialización ha hecho olvidar. Por ejemplo, en 1969 Eric Hobsbawm publicó Bandits. ${ }^{2}$ En parte, debido a la recepción de esta obra, los estudios sobre fenómenos comparables en América Latina discutieron con particular ahínco la categoría de bandido social. Richard Slatta, Paul Vanderwood y otros sumaron a aquélla la de "bandido político" y la cuestionaron con base en una variedad de expresiones regionales y locales

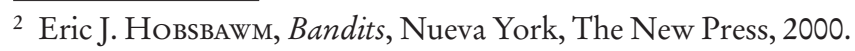


del bandidaje. ${ }^{3}$ Estos estudios recuperaban discusiones sobre violencia y procesos de construcción estatal nada extraños a los derroteros que tomarían los trabajos sobre criminalidad urbana algunos años más tarde.

De hecho, la emergencia de la criminología como saber científico -y sobre todo el impulso de las penitenciarías- se sumó como campo de interés para una historiografía interesada en marginación, violencia y desigualdad en tanto fenómenos que acompañaron la urbanización y modernización de finales del siglo xIx. Es injusto dejar de mencionar a quienes protagonizaron ese impulso-Carlos Aguirre, Marcos Bretas, Robert Buffington, Lila Caimari, Pablo Piccato, Elisa Speckman, Jorge Trujillo y un largo etcétera-, pero la lista inevitablemente permanece corta. Con todo, hubo esfuerzos colectivos y otros individuales cuya referencia suele reiterarse en la reformulación de ejes que discuten la trasgresión y el control en su relación con el Estado, la sociedad, la conflictividad jurídica y los procesos judiciales, lo mismo que la construcción social del crimen y algunos significados del castigo. ${ }^{4}$ Acaso un desplazamiento fundamental toca al estudio de las

${ }^{3}$ Richard W. SLatTA (ed.), Bandidos: The Varieties of Latin American Banditry, Nueva York, Greenwood, 1987. Para la región andina véanse: Carlos AguirRe, Charles Walker y Carmen Vivanco, Bandoleros, abigeos y montoneros. Criminalidad y violencia en el Perú, siglos XVIII-XX, Lima, La Siniestra, 2019.

${ }^{4}$ Ricardo D. Salvatore, Carlos Aguirre y Gilbert M. Joseph (eds.), Crime and Punishment in Latin America: Law and Society since Late Colonial Times, Durham, Duke University, 2001; Carlos Aguirre y Robert Buffington, Reconstructing Criminality in Latin America, Wilmington, Scholarly Resources, 2000; Marcos L. BReTAS, A guerra das ruas: povo e polícia na cidade do Rio de Janeiro, Prêmio Arquivo Nacional de Pesquisa, Ministério da Justiça, Arquivo Nacional, 1997; Lila CaImari, Apenas un delincuente: crimen, castigo y cultura en la Argentina, 1880-1955, Buenos Aires, Siglo Veintiuno Editores, 2004; Pablo Piccato, City of Suspects: Crime in Mexico City, 1900-1931, Durham, Duke University, 2001, y Elisa SPeckman, Crimen y castigo: legislación penal, interpretaciones de la criminalidad y administración de justicia, Ciudad de México, 1872-1910, México, El Colegio de México, Universidad Nacional Autónoma de México, 2002. 
policías. Es cierto que no habían sido obviadas, pero en tiempos más recientes han merecido una atención inusitada que reflexiona desde su diseño institucional, su composición social hasta sus prácticas de escritura y mediación frente a la sociedad urbana.

En suma y en un sentido bastante general, las colaboraciones reunidas en este dossier forman parte de propuestas recientes en la historiografía del delito, la justicia, las policías y el castigo. Desde la década de 1970 y con divergencias locales, se han abierto ejes de un repertorio que va del bandidaje a la criminalidad urbana, asuntos sobre los cuales se ha acumulado una abundante cantidad de estudios, algunos de los cuales son sumamente valiosos para entender, en perspectiva histórica, mecanismos de control y resistencia, marginalidades y violencias, así como procesos de construcción estatal.

Dentro de esa agenda, han sido menos atendidos los delitos económicos y monetarios: desde la llamada criminalidad de "cuello blanco" hasta la falsificación de dinero y las estafas interpersonales. En tal sentido, el propósito de los artículos que conforman este dossier es atender transgresiones económicas que acusan una serie de rasgos y expresiones concretas: 1) Fueron cometidas por delincuentes de clases medias y altas. 2) Su principal motivación fue la ganancia monetaria y la valorización financiera. 3) Demuestran cierto grado de profesionalización y organización, pero rara vez supusieron el ejercicio directo o la amenaza de violencia física, a diferencia de formas de crimen organizado como las mafias y los cárteles. 4) Por lo general, entrañaron el abuso de confianza en transacciones monetarias. 5) Por último, fueron encubiertos y, comúnmente, la victimización fue difusa. Se trata, entonces, de características que, además de apreciarse en las prácticas, supusieron la emergencia y circulación de saberes policiales técnicos. 